\title{
THREE-DIMENSIONAL MAPPING OF AN ANCIENT CAVE PAINTINGS USING CLOSE-RANGE PHOTOGRAMMETRY AND TERRESTRIAL LASER SCANNING TECHNOLOGIES
}

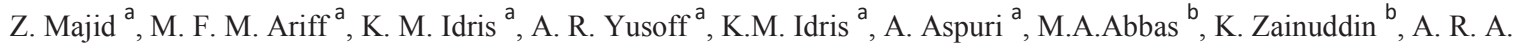 \\ Ghani $^{\mathrm{c}}, \operatorname{Ardi}^{\mathrm{C}, *}$ \\ ${ }^{a}$ Geospatial Imaging and Information Research Group, Universiti Teknologi Malaysia, MALAYSIA - zulkeplimajid, mfaridma, \\ khairulnizami@utm.my

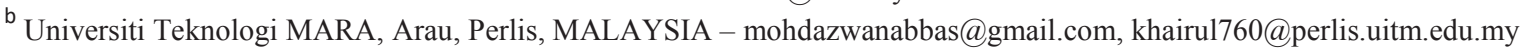 \\ ${ }^{\mathrm{c}}$ Department Of National Heritage, MALAYSIA - ardi, rasidi@heritage.gov.my
}

Commission II

KEYWORDS: three-dimensional, cave painting, terrestrial laser scanning, close-range photogrammetry, non-contact

\begin{abstract}
:
The paper describes the used of close-range photogrammetry and terrestrial laser scanning technologies as an innovative technology for acquiring the three-dimensional data of an ancient cave paintings. The close-range photogrammetry technology used in the research was divided in two categories which are the UAV-based close-range photogrammetry and the terrestrialbased close-range photogrammetry. The UAV-based technology involved with the used of calibrated Phantom 4 System while the terrestrial-based technology involved with the calibrated Sony F828 digital camera and pPhotoModeler software. Both stereo and convergent image acquisition techniques were used to acquire the images of the paintings. The ancient cave paintings were also recorded using terrestrial laser scanning technology. In the research, the FARO Focus 3D terrestrial laser scanner was used to capture the three-dimensional point clouds and images of the paintings. The finding shows that both close-range photogrammetry and laser scanning technologies provide excellent solutions to map and to record the ancient paintings. As compared to the conventional method, both close-range photogrammetry and terrestrial laser scanning technology provide a noncontact solution for data acquisition and the data was recorded in digital format for better protection and security.
\end{abstract}

\section{INTRODUCTION}

Malaysia is known as one of the historical country in the Asian region. One of the historical artifacts is the ancient cave paintings. In Peninsular Malaysia, there are 15 historical caves with ancient paintings, located at four states. The states are Perak, Kedah, Pahang and Kelantan. The most excited cave ancient paintings were located at the Ipoh and Lenggong areas in Perak state. In Ipoh, Tambun Cave is the most popular site where the ancient paintings were drawn on the cave's wall at 30 meters height from the ground. At Lenggong district, the Dayak and Badak caves are the most popular historical caves with more than hundreds ancient paintings.

Archaeologists at the Department of Heritage Malaysia used conventional methods to record the paintings. The tracing paper was used to trace the paintings in order to produce a recorded document with the true dimension of the paintings. The digital camera was also used as a tool to record the paintings. The disadvantages of the conventional methods are (1) the material used to record the paintings (tracing paper) is exposed to damage and lost problems, (2) the recorded paintings is out of scale and cannot be used for the reconstruction process and (3) the archeologists was exposed to unsafe situation where they have to climb to get near to the paintings.
Nowadays, close-range photogrammetry and laser scanning become the most popular technologies for non-contact mapping and recording of three-dimensional objects. Close-range photogrammetry involved with the process of taking images from stereo and convergent angles using calibrated digital camera. While laser scanning make used of laser light to scan the three-dimensional object to produced three-dimensional point clouds data of the object. Close-range photogrammetry and laser scanning technologies has been used in many applications such as archaeology, engineering and industrial surveying, forensic mapping, medical applications and others. Therefore, the aim of the research is to evaluate the capability of the close-range photogrammetry and three-dimensional terrestrial laser scanning technologies for the mapping and documentation of ancient cave paintings.

In the research, Tambun, Dayak and Badak caves was selected as a case study.

\section{PHOTOGRAMMETRY AND LASER SCANNING AS DATA CAPTURE TECHNIQUE FOR CAVE PAINTINGS - A REVIEW}

According to Skoog et al (2016), the use of Terrestrial Laser Scanning (TLS) in combination with imagery is 
becoming increasingly common, with its applications spreading to a wider range of fields. In the research, terrestrial laser scanning data was integrating with the SLR digital images for the multispectral analysis of indigenous rock art. The research have found out that the terrestrial laser scanning become the tremendous method to be used for the acquiring of three-dimensional rock art data.

According to Gallay et al (2015), mapping and modeling the complicated geometry of caves is a challenging task that has traditionally been undertaken by tacheometric surveying methods. Terrestrial laser scanning (TLS) technologies can acquire millions of points represented by 3-D coordinates, at very high spatial densities on complex multifaceted surfaces within minutes. In the research, terrestrial laser scanning was used to map the complex cave rapidly. The $3 \mathrm{D}$ cave surface model generated from the TLS data was then used to analyze the volume of the selected area. The research have found out that the terrestrial laser scanning become the tremendous method to be used for the acquiring of three-dimensional cave surface.

According to Gallay et al (2016), laser scanning overcomes the problem of reaching high ceilings, providing new options to map underground landscapes with unprecedented level of detail and accuracy. In the research, terrestrial laser scanning method was used to carry out the geomorphometric analysis of cave ceiling channels. The researcher reported that the three-dimensional data improved the accuracy of the measurement of the ceiling channels.

According to McFarlane et al (2013), the integration of the three-dimensional laser scanning and an autonomous drone was the best solution for the surface mapping of Gomantong Caves in Sabah. According to Blistan et al (2016), photogrammetry in combination with UAVs and application of these technologies in geology for the documentation of inaccessible or large-scale natural or artificial geological outcrops appears to be a progressive solution in terms of accuracy and efficiency. The researchers have found out that there is an advantage of using low-cost UAVs and cameras when collecting geological data. The research also found that the UAVphotogrammetry was a suitable tool for the spatial data collection when documenting natural and artificial rock outcrops with high quality data for the creation of the threedimensional model.

\section{THREE-DIMENSIONAL MAPPING OF CAVE PAINTINGS USING CLOSE-RANGE PHOTOGRAMMETRIC TECHNIQUE}

The close-range photogrammetry technology used in the research was divided in two categories which are the UAVbased close-range photogrammetry and the terrestrial-based close-range photogrammetry.

\subsection{Data acquisition using UAV-based close-range photogrammetric technology}

The UAV-based close-range photogrammetry was used to capture the stereo images of the ancient cave paintings located at 30 meters high from the ground. The calibrated Phantom 4 digital camera was used in the research. Figure 1 shows the UAV-based close-range photogrammetry Phantom 4 System that has been used in the research. Figure 2 shows the DJI camera.

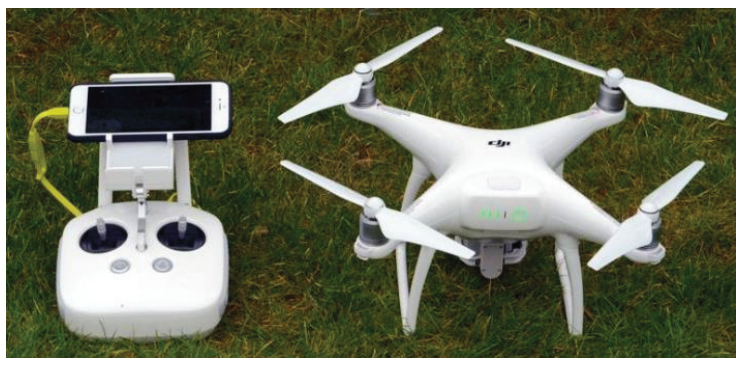

Figure 1: UAV-based close-range photogrammetry - DJI Phantom 4 System

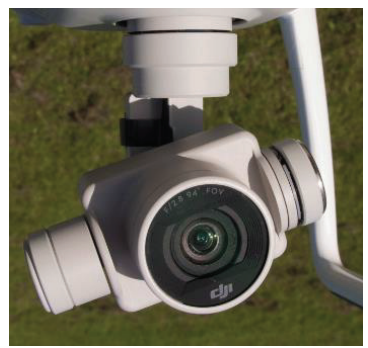

Figure 2: The DJI Phantom 4 digital camera

3.2 Digital processing and output visualization of UAVbased close-range photogrammetry data

The processing of the UAV-based close-range photogrammetric data was carried out using the Pix4D image processing software. The high resolution video images of the ancient paintings were converted to the still image format. Figure 3 shows the visualization of the output gained from the data processing task.

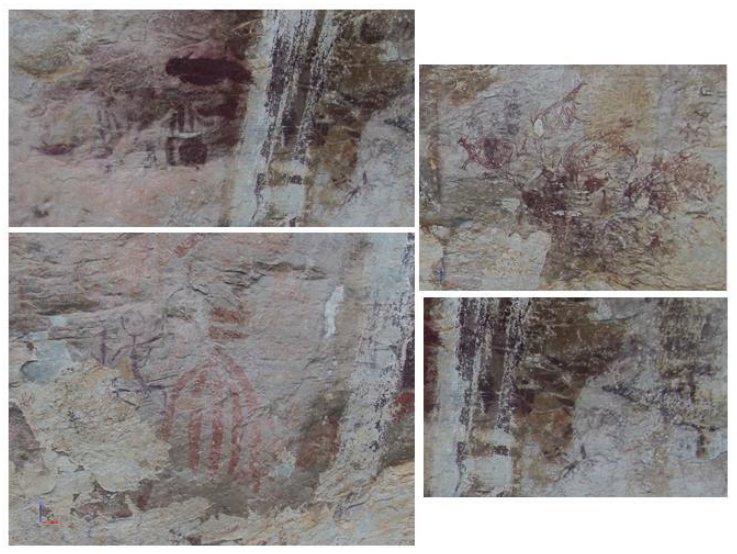

Figure 3: Visualization of the output gained from the UAVbased close-range photogrammetry yechnology 
3.3 Data acquisition using terrestrial close-range photogrammetric technology

The terrestrial close-range photogrammetry was used to capture the stereo images of ancient cave paintings located at the height of 1.5 to 2.0 meters from the ground. The calibrated Sony F828 digital camera was used for the terrestrial-based close-range photogrammetry. The photogrammetric coded targets and the natural targets were used in the research. Figure 4 shows the Sony F828 digital camera.

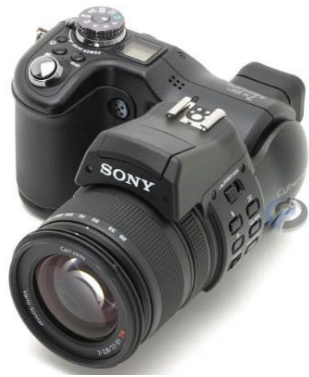

Figure 4: The Sony F828 digital camera

The Sony F828 digital camera was used in the research because the camera was setup with the wide angle CarlZeiss lens which provides the minimum lens distortions. Both the DJI Phantom 4 and the Sony F828 digital cameras were calibrated using the photogrammetric self-calibration method. Figure 5 shows the data acquisition of the ancient paintings using Sony F828 digital camera.

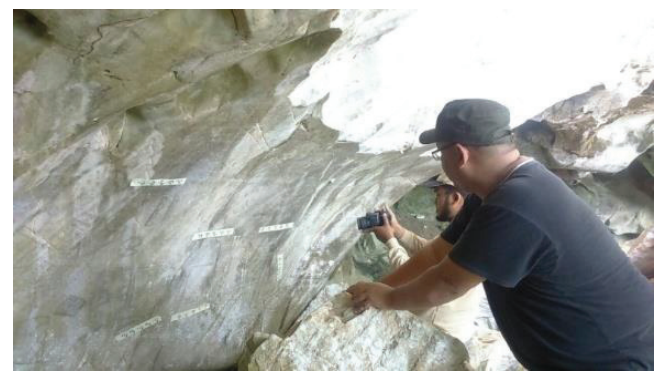

Figure 5: Data acquisition of the ancient paintings using Sony F828 digital camera

3.4 Digital processing and output visualization of terrestrial-based close-range photogrammetry data

The processing of the images taken from terrestrial-based close-range photogrammetry technology was carried out using PhotoModeler Scanner software. A minimum number of two images were used for data processing. Figure 6 shows the data processing task using the above mentioned software.

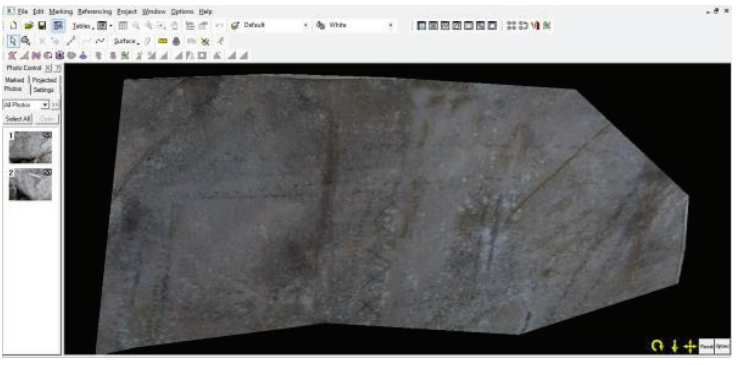

Figure 6: The processing of the terrestrial-based closerange photogrammetric data using PhotoModeler Scanner software

The results produced from the terrestrial-based close-range photogrammetry technology are the three-dimensional model of the ancient paintings. Figure 7 shows the visualization of the ancient paintings as the output from the terrestrial-based close-range photogrammetry technology.
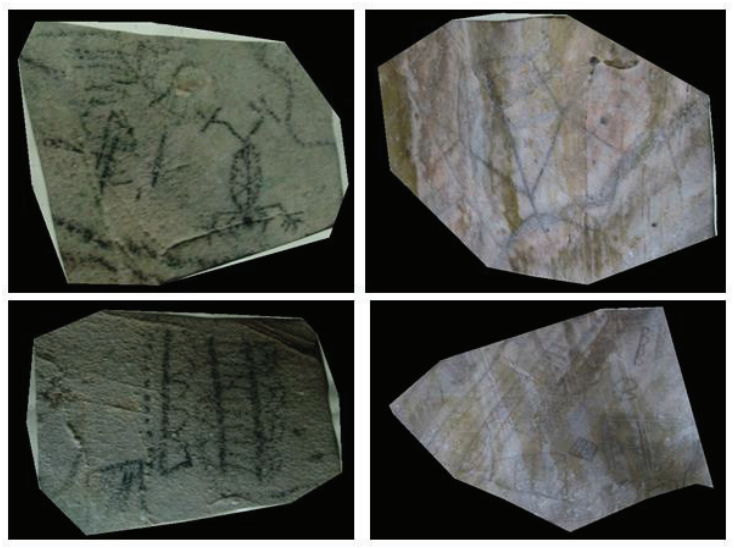

Figure 7: The visualization of the ancient paintings as the output from the terrestrial-based close-range photogrammetry technology

\section{THREE-DIMENSIONAL MAPPING OF CAVE PAINTINGS USING TERRESTRIAL LASER SCANNING TECHNIQUE}

The ancient cave paintings were also recorded using terrestrial laser scanning technology. In the research, the FARO Focus 3D terrestrial laser scanner was used to capture the three-dimensional point clouds and images of the paintings. The FARO Focus $3 \mathrm{D}$ system provides dense point cloud data with the scanning capability of 700,000 points per second. The scanner was also equipped with the built-in high resolution digital camera system for texture recording. Figure 8 shows the FARO Focus 3D terrestrial laser scanning system. 


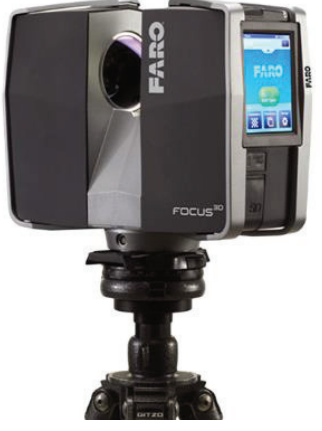

Figure 8: The FARO Focus 3D terrestrial laser scanning system.

\subsection{Data acquisition using terrestrial laser scanning} technology

During the data acquisition task, the sphere targets were setup at the few strategic locations near to the scanning area and the paintings was scanned at medium scanning resolution. Figure 9 shows the setup of the laser scanner and the positions of the sphere targets for the acquisition of the paintings.

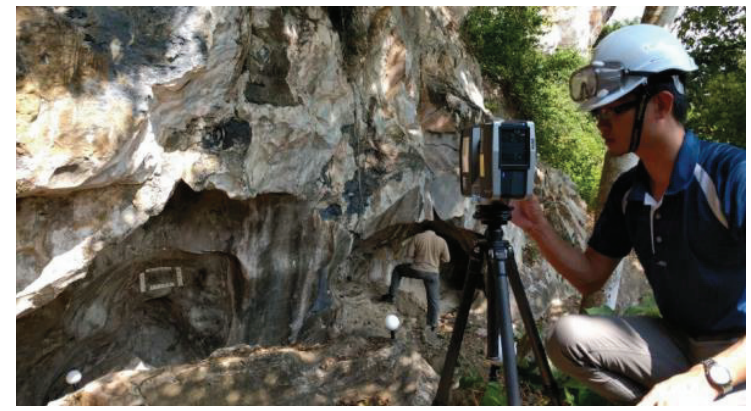

Figure 9: The setup of the laser scanner and the positions of the sphere targets for the acquisition of the paintings data

Figure 10 shows the plan view of the terrestrial laser scanning data. The figure also visualized the position of the scanning stations and the sphere targets.

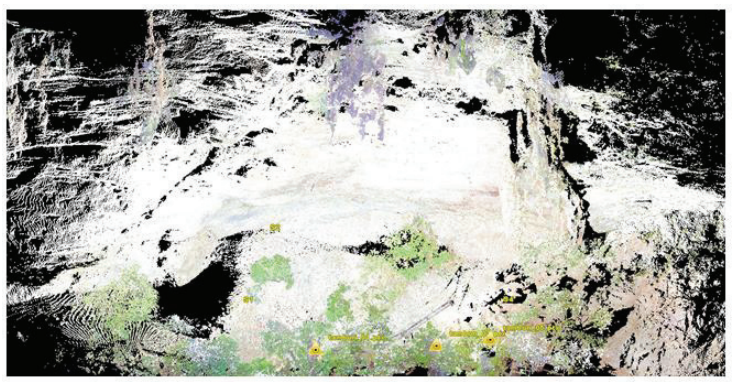

Figure 10: The plan view of the terrestrial laser scanning data (for Tambun Cave)

4.2 Data processing and output visualization of terrestrial laser scanning data

The scanning datasets was registered using the sphere targets. The registration process was carried out using the Faro Scene software. The final processing of the terrestrial laser scanning data involved with the generation of the colored point cloud output which integrate the registered point cloud data and the Red-Green-Blue (RGB) data captured by the built-in high resolution camera that was setup inside the scanner. Figure 11 shows the visualization of the terrestrial laser scanning output.

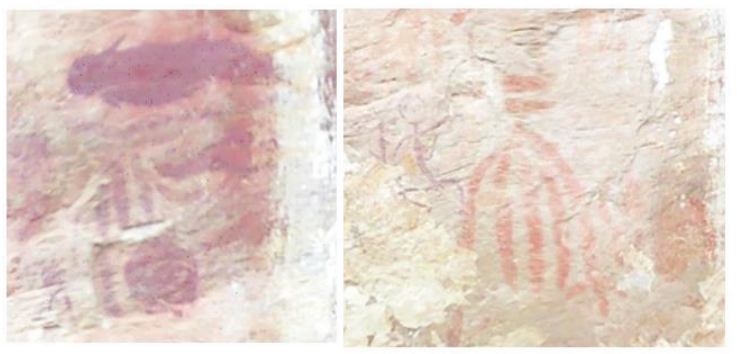

Figure 11: The visualization of the terrestrial laser scanning output of the ancient paintings

\section{COMPARISON ANALYSIS BETWEEN THE MAPPING METHODS}

Both three-dimensional model of the ancient cave paintings that was produced from the close-range photogrammetry and three-dimensional terrestrial laser scanning was compared. The comparison analysis was carried out by comparing the level of visualization quality of the paintings from two different technologies. Figure 12 shows the visualization comparison between the terrestrial laser scanning and UAV-based close-range photogrammetry outputs.

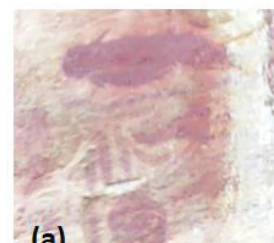

(a)

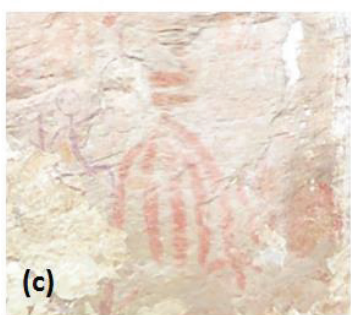

Figure 12: The visualization of terrestrial laser scanning (a) and (c), and the UAV-based close-range photogrammetry (b) and (d) outputs

The above figure shows that the visualization quality of the paintings generated from the UAV-based close-range photogrammetry is clearer as compared to the output 
generated from terrestrial laser scanning. In this issue, the paintings are located at $30 \mathrm{~m}$ height from the ground. The terrestrial laser scanner was setup on the ground and the scanning process was performed at the scanning distance of $60 \mathrm{~m}$. The problem regarding the visualization quality may arise because of the scanning angle and the resolution of the built-in camera inside the laser scanner.

The visualization quality of the output generated from the UAV-based close-range photogrammetry technology was very high. In this issue, the UAV can fly closer to the object. The resolution of the DJI camera plays an important role in acquiring high quality images of the paintings. As the information of the texture is very important for archaeologist, UAV-based close-range photogrammetry was selected to be the best solution for the acquiring of ancient paintings.

\section{CONCLUSION AND FURTHER WORKS}

The advantages of using close-range photogrammetry and terrestrial laser scanning for the mapping and recording of ancient cave paintings are (a) both close-range photogrammetry and terrestrial laser scanning technologies provide a non-contact method for capturing the data of the paintings, (b) both close-range photogrammetry and terrestrial laser scanning technologies provide high accuracy and high resolution three-dimensional model of the paintings and (c) both close-range photogrammetry and terrestrial laser scanning technologies provide fast and accurate data capture method. Last but not least, both close-range photogrammetry and the terrestrial laser scanning technologies has become the most suitable technology to be used in mapping and recording of the ancient cave paintings with true geometry and texture. The comparison analysis shows that both technologies provide the similar results.

According to archaeologists from the Department of National Heritage, Malaysia, the recent paintings is located at the current layer on the rock surface at the Tambun cave. The cave paintings history of the Tambun cave mentioned that there are few hidden painting layers overlapped with the current paintings and it can't be seen by our normal eye. The research will be continued with the development of an imaging sensor that can be used to acquire the hidden paintings.

\section{ACKNOWLEDGEMENT}

The authors would like to thank the Ministry of Higher Education (MOHE) for providing the fund from vote number Q.J130000.2527.4L149. The authors would also like to thank the Geospatial Imaging \& Information Research Group and the Faculty of Geoinformation \& Real Estate UTM.

\section{REFFERENCES}

Skoog B, Helmholz P \& Belton D (2016), Multispectral Analysis Of Indigenous Rock Art Using Terrestrial Laser Scanning, The International Archives of the Photogrammetry, Remote Sensing and Spatial Information Sciences, Volume XLI-B5, 2016 XXIII ISPRS Congress, 12 19 July 2016, Prague, Czech Republic, 405-412

Gallay M, Kanuk J, Hochmuth Z, Meneely J.D, Hofierka J \&Sedlak V (2015), Large-scale and high-resolution 3-D cave mapping by terrestrial laser scanning: a case study of the Domica Cave, Slovakia, International Journal of Speleology, 277-291

Gallay M, Hochmuth Z, Kaňuk J, \& Hofierka J (2016), Geomorphometric analysis of cave ceiling channels mapped with 3-D terrestrial laser scanning, Hydrol. Earth Syst. Sci., 20, 1827-1849

McFarlane D.A, Buchroithner M, Lundberg J, Petters C, Roberts W \& Van Rentergen G (2013), Integrated ThreeDimensional Laser Scanning And Autonomous Drone Surface- Photogrammetry At Gomantong Caves, Sabah, Malaysia, 16th International Congress of Speleology, July 2013.

Blistan P, Kovanič L, Zelizňaková V \& Palková J (2016), Using UAV photogrammetry to document rock outcrops, Acta Montanistica Slovaca Volume 21 (2016), number 2, $154-161$ 